\title{
Oral health protocol for liver transplant patients
}

Liliane Lins $^{1^{*}}$ and Jorge Bastos ${ }^{2,3}$

*Correspondence: liliane.lins@ufba.br

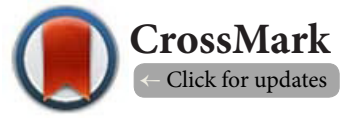

'Department of Preventive Medicine, Faculty of Medicine, Federal University of Bahia, Salvador, Bahia, Brazil. ${ }^{2}$ Department of Anesthesiology and Surgery, Faculty of Medicine, Federal University of Bahia, Salvador, Bahia, Brazil.

${ }^{3}$ Gastroenterology and Hepatology Unit, Portuguese Hospital, Salvador, Brazil.

\begin{abstract}
Chronic liver disease and cirrhosis were the ninth leading cause of death in Brazil in 2011. Infectious complications are major factors for morbidity and mortality in liver transplant recipients. Oral infection is a cause of systemic infection for both liver transplant candidates and recipients. Liver transplant patients are at high risk of oral infection and preventive measures are mandatory. Oral treatment is feasible to the majority of patients awaiting liver transplantation. However, protocols for oral lesions management in liver transplant patients are not established in literature yet. The aim of the present study is to describe an oral health protocol for liver transplant patients based in our 12 years of experience in diagnosing and treating oral disease in the Liver Transplantation Clinic, Federal University of Bahia, Brazil. This protocol was developed by a multidisciplinary team of transplant surgeons, hepatologists, transplant nurses and dentists. All patients are evaluated by the hepatology team that assess liver disease severity and refer them to oral care. The oral assessment is carefully carried out. Additional complementary examinations are necessary to conclude diagnosis and proceed to an individual treatment plan. When oral surgery is necessary, coagulation factors, liver disease severity and the extent of surgical procedure are evaluated for each patient.
\end{abstract}

Keywords: Liver transplantation, oral health, treatment protocols, chronic liver disease

\section{Introduction}

Chronic liver disease (CLD) and cirrhosis were the ninth leading cause of death in Brazil in 2011. This position in the mortality rank was estimated by considering the number of deaths attributed to chronic viral hepatitis, liver malignancies tumor, liver alcoholic disease, non-alcoholic chronic hepatitis and liver cirrhosis in the reported year [1].

Portal hypertension $(\mathrm{PH})$ is the principal consequence of cirrhosis. From $80 \%$ to $90 \%$ of asymptomatic cirrhotic patients are estimated to have an increase in the hepatic venous pressure gradient. Decompensated liver disease, as complication of $\mathrm{PH}$, is associated to esophageal or gastric varices, variceal bleeding, ascites, spontaneous bacterial peritonitis, hepatorenal syndrome, portopulmonary hypertension, hepatopulmonary syndrome, hepatic encephalopathy, portal hypertensive gastropathy, enteropathy and colopathy; and disturbances in the liver metabolism. The severity of $\mathrm{PH}$ complication represents the first cause of hospital admission, death and liver transplantation [2]. Infectious complications are major factors for morbidity and mortality in liver transplant recipients [3].
Oral infection is a potential risk of systemic infection for both liver transplant candidates and recipients $[4,5]$. Oral treatment is feasible to the majority of patients awaiting liver transplantation. However, protocols for oral lesions management in these patients are not established in literature yet [4].

The aim of the present study is to describe an oral health protocol for liver transplant patients based in our 12 years of experience in diagnosing and treating oral disease in these patients.

\section{Review}

Systemic complication from oral bacterial infection

Odontogenic infections are associated with systemic diseases $[6,7]$. The advancement on the classification and detection of oral microorganisms that are restricted, in normal conditions, to the oral cavity has highlighted the importance of considering oral foci as a possible source of systemic complications. Chronic periodontal diseases are among the most prevalent chronic infections in humans. Oral infection can also be the site of origin for spreading pathogenic microorganisms to distant 
Lins et al. Transplantation Technology 2014,

body sites, especially in immunocompromised individuals.

Other complications, such as brain and liver pyogenic abscess, have also been related to oral infections [8-11]. Although approximately $50 \%$ of pyogenic liver abscess (PLA) cases are considered as cryptogenic, PLA formation is generally attributed to the transmission of infection via three major routes: biliary tract, portal vein, and hepatic artery [9]. Recent reports have associated periodontal disease to PLA. A female patient with history of chronic periodontal disease that suffered a cardiopulmonary arrest was investigated by autopsy. Several periodontopathic bacterial species in the PLA were identified, including Fusobacterium nucleatum, Treponema denticola, Prevotella intermedia and Porphyromonas gingivalis [9]. Another case reported that Fusobacterium nucleatum was the etiologic agent for LPA in an immunocompetent patient with periodontal disease [10].

The evolution of periodontal disease may lead to periodontitis characterized by inflammation and infection of the ligament and alveolar bone supporting the teeth. Periodontal pathogens, inflammatory mediators produced in periodontal tissues, might enter the bloodstream, causing systemic effects. Chronic periodontitis has been suggested as a risk factor for cardiovascular diseases, bacterial endocarditis, diabetes mellitus, and respiratory disease, among others $[6,7,12,13]$. Tobacco smoking, demographic factors, socio-economic status, several general diseases, multiple drug use and psychological stress are risk factors for periodontitis [13].

Many factors may trigger odontogenic bacteremia, evidencing the necessity of antibiotic prophylaxis in immunocompromised patients. Some risk practices are routinely performed by patients, such as chewing and tooth brushing; others are inherent to dental treatment, such as periodontal procedures, tooth extractions, insertion of orthodontic appliances and endodontic procedures [6,14]. Odontogenic bacteremia is transient, ranging 30-60 minutes, in blood [15-21]. However, in immunosuppressed patients, microorganisms from the infe- cted site may reach peripheral capillary system and organs, such as heart and lungs, in less than 1 minute after an oral procedure [6].

Oral bacteria are derived from highly specialized and distinctive communities of organisms that reside on a variety of different environmental niches in the human mouth, such as mucosal surfaces of the tongue, cheeks, palate, tonsils and dental microbial biofilms. Dental biofilm is predominately composed by anaerobic Gram negative species that induces a local and systemic inflammatory response, leading to periodontal tissue destruction. The periodontal microbiota is particularly heterogeneous; over 400 species have been identified by molecular biology methods. However, a significant proportion of the total oral microbiota remains unculturable [22].

A study has determined the prevalence and levels of 11 pathogenic bacteria associated with systemic diseases in subgingival dental biofilms obtained from periodontal sites of subjects with chronic periodontitis and periodontal health, using the checkerboard DNA-DNA hybridization technique. Predominant species identified were Corynebacterium diphtheriae, Enterococcus faecalis, Staphylococcusaureus, Acinetobacter baumannii and Escherichia coli. Most of the species were detected in higher prevalence and in more severe infection levels among patients with periodontitis. In particular, C. diphtheriae, E. coli, E. faecalis, P. aeruginosa and $S$. aureus were significantly more prevalent and detected in higher counts in diseased sites of patients with periodontal disease, compared to healthy subjects $(p<0.05)$. These results suggest that the oral cavity can act as a reservoir of pathogenic species of bacteria that may cause infection in distant body sites [23].

Standardized dental care should be recommended to all transplant patients, not only to those awaiting transplantation, but also during immunosuppressive therapy after surgery. A survey comprising 294 transplants centers in United States have shown that $38 \%$ of the centers reported at least one occurrence of dental infection prior transplantation that have postponed transplant surgery. At least one case of posttransplantation sepsis related to oral infection was reported by $27 \%$ of the centers and $83 \%$ recommended antibiotic prophylaxis in any case of transplantation [5]. A study among liver transplant candidates found high prevalence of poor oral health status and odontogenic antibiotic prophylaxis, periodontal treatment, and treatment of periapical lesions or abscesses. Extraction of root fragments was associated with reduction in mortality $(p<0.001)$, particularly in patients with advanced liver disease [4].

\section{Oral health in liver transplantation candidates and transplanted subjects}

It is a consensus in literature that cirrhotic patients have poor oral health status [4]. In 1996, an Italian study has proposed a guideline to evaluate oral health status in liver transplant candidates [24]. This study has pointed out the increased risk of infection by immunosuppression in liver recipients and the necessity to evaluate their dental health prior liver transplantation. Patients presented very poor dental hygiene $(85 \%)$, advanced periodontal disease (45\%), dental caries (67\%) and periapical lesion (20\%). Dental treatment guidelines before transplantation were described, and antibiotic pro-phylaxis before invasive dental procedures was recommended, but no protocol for severe liver disease was proposed.

The risk of operating a cirrhotic patient should be considered more carefully, because of the possibility of bleeding and infection [25]. A German study with 80 liver transplant candidates reported poorer oral health among the alco holics. High rate of complications after treatment prior to transplantation, frequently among alcoholic and Child-Pugh stage $C$ patients, recommends extra care with radical prophylactic dental sanitation. According to these authors, only absolutely necessary sanitation should be carried out prior to transplantation [25]. 
A study with 300 liver transplant candidates investigated the presence of gingivitis, dental plaque, dental caries, periodontal disease, edentulism, and xerostomia. Out of these 300 patients, $31.7 \%$ had viral hepatitis, $26 \%$ had alcoholic cirrhosis, and the prevalence of dental disease was similar to that found in the other liver transplant candidates, showing other liver disorders. Relevant risk factors for plaque-related gingivitis and caries included intervals of more than 1 year since the last dental examination, smoking, and diuretic therapy. These aspects are related to inadequate oral hygiene and reduced salivary flow [26].

In our study among 131 cirrhotic patients awaiting liver transplantation in Bahia, Brazil, we found high prevalence of poor oral health status and odontogenic infections, high alcohol consumption (71\%) and smoking (50\%). Out of these patients, $99 \%$ were partially edentulous; $51 \%$ had chewing difficulties; $48 \%$ experienced reduced salivary flow, $25 \%$ had periodontitis, $48 \%$ had periapical lesion, $49 \%$ had abscesses, and $45 \%$ had root fragments. The most frequent indication for liver transplantation was cirrhosis secondary to hepatitis C virus infection (42\%) and alcoholic liver disease (30\%), both associated to poor oral health. Twenty-one patients were lost of follow-up. Out of the remaining 110 patients, 63(57\%) underwent dental treatments with complications in only two cases. Our results have shown favorable outcomes with few complications and low mortality among the group of treated patients (treated patients, $31 \%$ versus $79 \%$ in untreated patients). Treatment of oral lesions that could represent a source of systemic infection was feasible in the majority of the patients and it was associated with mortality reduction, strengthening the necessity of an established protocol [4]. Although there is greater risk of bleeding in cirrhotic patients, we have treated all patients, performing surgical procedures during hospitalization, using blood products whenever indicated, using a multidisciplinary approach. Therefore, oral infection, such as periapical lesion, abscess e/or periodontal disease, was not treated with antibiotic therapy solely.

The risk of infection in post liver transplant without pretransplant dental treatment was evaluated in a retrospective study. Fifty-one subacute liver failure patients were included in the study. Thirty-five patients did not have dental examination and 16 had been treated for dental foci prior to liver transplantation. Twenty-six (74\%) out of the 35 patients, had 60 infections episodes, comparing with 13 infections episodes in $7(43 \%)$ treated patients. The infection incidence rate was 2.7-fold higher in the untreated group than in the treated one [27].

Oral cancer prevention in immunosuppressed patients Oral mucosal lesions are also frequent in cirrhotic patients. This fact indicates the needing of dental examination in order to prevent oral cancer, especially in cases of trauma associated with poor hygiene. A male liver transplant recipient, receiving tacrolimus ( $5 \mathrm{mg} /$ day) and prednisone ( $20 \mathrm{mg} /$ day), presented leukoplakia on the floor of the mouth four months after transplantation; four months later, a squamous cell carcinoma has developed at the site of this lesion. The rapid transformation of the lesion suggested that immunosuppression in transplanted patients with premalignant lesion must be considered as an important risk factor for oral cancer [28].

Literature also reports an increased risk of skin/lip cancer and other solid tumors after liver transplantation, associated with older age and the use of immunosuppression. A review of medical records of 174 liver transplanted patients reported that $21(12 \%)$ had developed 23 malignancies. Skin and lip cancer accounted for $12(52 \%)$ of the 23 malignancies. The cumulative risk for malignancy was $6 \%, 20 \%$, and $55 \%$ at 5 , 10 , and 15 years after transplantation, respectively. The overall relative risk as compared with the general population was 4.3(95\% confidence interval: 2.4-7.1) [29]. The incidence of tumors in 605 liver transplanted patients was 21(3.5\%) tumors in 20(3.3\%) recipients. Fourteen were nasopharyngeal and upper digestive tumors (three in floor of the mouth, two in tonsil, one in tongue, one in pharynx, three in larynx, and four in esophagus) and seven were lung tumors. Males presented higher incidence of nasopharyngeal tumors, associated with smoking and transplantation due to alcoholic cirrhosis. Nineteen patients were men, mean age at transplantation of $47.7 \pm 8.6$ years. Considering risk factors, $70 \%$ were heavy smokers, $75 \%$ were heavy drinkers, and $70 \%$ developed acute rejection. The incidence of these tumors was significantly higher in transplanted patients due to alcoholic cirrhosis compared to those transplanted due to nonalcoholic cirrhosis (8.1\% vs $0.8 \% ; \mathrm{P}<0.0001)$ [30].

\section{Oral manifestations of fungal and viral infections in immunosuppressed patients}

The occurrence of fungal, viral infection and lip lesions in immunosuppressed patients has been reported in literature. Patients' immunodeficiency and virulence of fungi pathogens may result in candidiasis as a complication in organ transplant recipients [31]. Cases of denture stomatitis lesions [4] were associated with poor hygiene in the upper denture prosthesis, corroborating with findings in the literature that associates poor hygiene to the proliferation of Candida albicans [32]. Regular oral examination and mycologic tests are recommended for liver transplant candidates or transplanted subjects. Predisposition to increased density of Candida spp. colonies in kidney or liver transplantations has been reported [33]. Besides, invasive fungal infection is associated with increased morbidity and mortality following liver transplantation. Candida albicans seems to be the most common pathogen. Therefore, prophylaxis is highly recommended for these high-risk patients, when infection is presumed [34].

Survival rates in transplantation have increased after immunosuppressive therapy. Concomitantly, the use of immunosuppressant such as cyclosporine A, tacrolimus, everolimus and mycophenolate mofetil has been associated to gingival 
Lins et al. Transplantation Technology 2014,

overgrowth and stomatitis [35-39]. A multidisciplinary approach is essential to evaluate and diagnose these lesions. A significant correlation between cytomegalovirus infection (CMV) infection and oral lesions in transplanted patients has been reported. The study comprised 25 immunosuppressed liver or kidney transplanted patients with stomatitis (mean age 13 years \pm 4 years). Dental examination, mycological tests and blood tests for CMV infection were performed in all patients. In situ CMV was found in $13(46 \%)$ out of 18 patients with oral mucosal ulceration. Candida albicans was identified in two cases. DNA of CMV was found in-situ in $5.5 \%$ of all biopsies, and in $9 \%$ of the biopsies of patients with clinical CMV infection [40]. An atypical oral presentation of herpes simplex virus infection in a 49-year-old woman after liver transplantation has also been reported [41]. The clinical differential diagnosis included chronic hyperplastic candidiasis, nodular leukoplakia and malignant neoplasm. An excisional biopsy confirmed herpes virus infection by immunoperoxidase staining. Oral stomatitis in transplanted patients could be associated with type of immunosuppressive medication, viral or Candida albicans. In some cases, replacement or decreasing the dosage of immunosuppressive drugs is necessary $[35,36,42]$.

A pathogenic role of human herpesviruses such as EpsteinBarr virus (EBV) and CMV has been showed by literature. Forty samples with apical periodontitis were analyzed by polymerase chain reaction. EBV was detected in apical periodontitis lesions at significantly $(p<0.0001)$ higher frequencies $(72.5 \%$ and $50 \%$, respectively) than in controls (both $2.5 \%$ ). CMV detection was rare in both apical lesions $(10 \%)$ and controls (0\%) [43]. The EBV replication in oropharyngeal epithelial cells seems to be infrequent. When it occurs, an impairment of the immune system may have allowed EBV replication, since it has been shown that individuals with evidence of EBV replication were either on immunosuppressive therapy or were terminally ill cancer patients [44]. More than 70\% of post-transplant lymphoproliferative disorder (PTLD) are related to EBV. EBV mucocutaneous ulcer (EBV MCU) is a B-cell lymphoproliferative disorder that can occur in elderly or immunocompromised patients. A cohort of 70 transplant recipients with EBV PTLD presented 7 patients with EBV MCU. EBV MCU was observed in oral mucosa in 4 and gastrointestinal tract in 3 transplant recipients. Although none of patients had liver transplantation, it was the first report concerning EBV MCU in solid transplant recipients. Lesions were treated with reduction of immunosuppression, surgical resection, rituximab monotherapy or rituximab or Velcade chemotherapy. Appropriate diagnosis is necessary to treat accordingly [45].

\section{Bone loss and cirrhosis}

Loss of bone mass has been also reported as cirrhosis complication [46]. It is important to notice that, in this research, not only patients with liver cirrhosis had bone loss, but also the liver transplanted subjects when compared to health individuals. However, the post transplantation group had significantly less bone loss than the liver cirrhotic patients. Authors suggest that these results might be attributed to restoration of liver function and reduced cytokine levels.

\section{Oral diagnosis and treatment protocol in chronic liver disease}

Liver transplant candidates are often in end-stage cirrhosis presenting coagulation disorders, protein synthesis reduction, and immunodepression. There are no uniform guidelines in literature for oral treatment of liver transplantation patients. It is necessary to establish a multidisciplinary treatment, considering disease prognosis, the severity of the underlying hepatic disease, and the organ extrahepatic function.

Patients awaiting transplantation must be evaluated and treated for cirrhosis-related complications to maintain overall health, including oral health. In Brazil, poor oral health may disable candidates for liver transplantation. In addition, oral infections can decompensate cirrhosis, increasing health care costs. Cost-efficient management of cirrhosis-related complications should be an economic priority, since the cost for treatment of decompensated cirrhosis patients is substantially higher than that of patients with compensated cirrhosis [47].

The attention to oral complications in liver transplant candidates is justified by several reasons: cirrhotic patients generally use multi-drug therapy which can reduce salivary flow and contribute to periodontal disease, caries, candidiasis and other oral lesions [48]; the main cause of liver disease in Brazil and in many part of the world is cirrhosis due to Hepatitic C Virus (HCV) infection followed by Alcoholic liver disease (ALD) which are associated with reduced salivary flow and untreated dental conditions or personal behaviors that are risk factors for dental diseases $[4,26,27,49]$; oral infection may decompensate cirrhosis and may contribute to the development of $\mathrm{PH}$ complications such as hepatic encephalopathy and hepatorenal syndrome; if preventive actions for oral health are not effective, the treatment of oral foci generally requires hospitalization and transoperative blood requirements $[4,25]$; studies has demonstrated the relationship between oral health and systemic health [4,6-13] and the economic impact of oral complications is too high in cirrhotic patients $[4,47]$.

Oral diagnosis and treatment protocol in Liver Transplant Patients is described followingly (Figure 1).

\section{Examination}

Medical and dental history should include complete evaluation: indication for liver transplantation, presence of ascites, history of hepatorenal syndrome, variceal bleeding, hepatic encephalopathy and spontaneous bacterial peritonitis. Laboratory examinations, cirrhosis etiology and MELD (Model for EndStage of Liver Disease) must also be evaluated. The history of lesion in oral mucosae, medication adverse effects, xerostomia, oral habits, and the use of mouthwashes and toothpaste must 


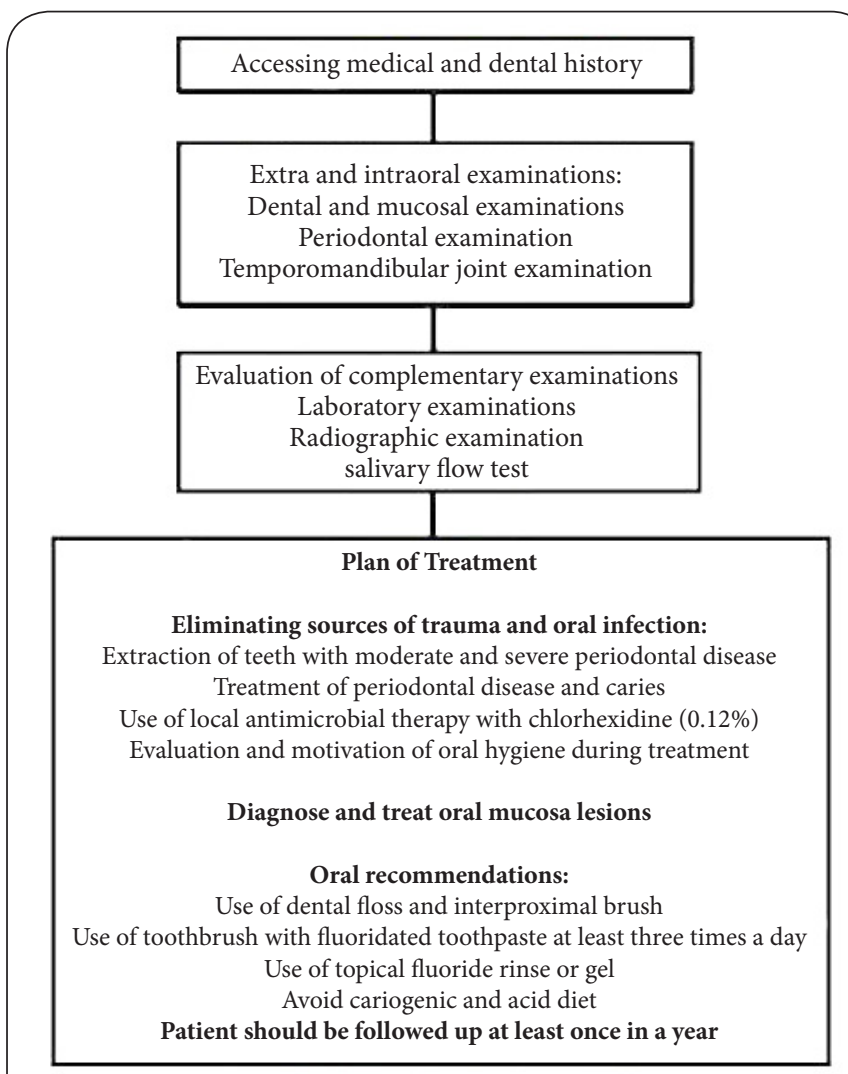

Figure 1. Fluxogram for oral diagnosis and plan of treatment in liver transplantation patients.

be investigated.

\section{Extra and intraoral examination}

Extra oral examination must observe facial asymmetry, temporomandibular joint disorders, and facial area should be palpated. In addition, examination of lymph node groups should be included: anterior cervical, posterior cervical, tonsillar, submandibular, sub-mental and supra-clavicular.

Intraoral examination must explore the oral cavity, including cheeks, hard palate, soft palate, and maxillary sinus. Pain on palpation of the maxillary teeth is a symptom associated with sinusitis. Oral mucosa should be evaluated carefully along the upper and lower gum lines and at the mucosa in general.

\section{Periodontal examination and dental caries score}

All liver candidates should be submitted to full mouth assessment of periodontal status. We adopted the World Health Organization (1997) criteria and the European Asso-ciation of Dental Public Health Standards, using the last one to define the severity of periodontitis [50-52]. The following parameters must be evaluated in each patient: clinical attachment loss, probing pocket depth, tooth mobility, and number of decayed/missing/ filled teeth (DMFT index).Superficial caries and those without dental pulp involvement should be treated immediately. When dental pulp is affected, associated periodontal disease must be investigated, as well as liver disease severity, in order to decide between endodontic treatment or surgical extraction [4].

\section{$\mathrm{X}$-ray diagnosis}

All patients should undergo panoramic radiography. Accessing radiographic examinations is important to diagnose intraosseous lesions and other asymptomatic occurrences not identified by palpation. These conditions should be treated by taking into account the liver disease severity as described below.

Identifying reduced salivary flow and related pathologies We use the method described by Krasse [53]. In the salivary flow examinations, a flow between 1 and $3 \mathrm{ml} / \mathrm{min}$ is classified as normal, while less than $1 \mathrm{ml} / \mathrm{min}$ is reduced. If salivary flow is reduced, the patient may have a decrease in the following salivary functions: remineralization capacity, antimicrobial capacity, cleansing of the mouth and pH buffer capacity. Difficulties with deglutition, mastication and taste alteration may occur. For xerostomia management in cirrhotic patients, the use of salivary substitute or systemic sialagogue medication depends on the underline systemic disease and comorbidities. Adequate hydration and avoidance of potential oral mucosal irritants are also recommended [54].

Decreased salivary output has a direct correlation with periodontal disease, caries, mucosa lesions and candidiasis. When periodontal disease and caries are diagnosed, they must be treated accordingly and surgical procedures need further evaluation. Oral mucosa lesions should be diagnosed and the possibility of trauma association must be considered. The use of appropriate topic medication is indicated. Diagnosis of oral candidiasis should be performed and treated. Nystatin suspension is the most available medication in Brazil. Cirrhotic patients with diabetes should be instructed not to swallow nystatin because it contains sugar. Systemic treatment should be discussed with the hepatology team, since renal function must be evaluated prior to medication use.

Considering CMV or EBV infections, before starting chemotherapy to treat these viruses, reduction of immunosuppression is recommended [45]. In case of Herpes Simplex Virus (HSV), acyclovir therapy is an effective and less expensive option in treatment.

Risk of bleeding and infection related to oral surgery Thrombocytopenia in patients with CLD has multifactorial etiology, including splenic sequestration of platelets, bone marrow suppression of platelets and decreased thrombopoietin. Liver damage leads to decreased production of clotting factors (fibrinogen, prothrombin, factors V, VII, IX, X, XI, protein C and antithrombin) and increased risk of bleeding [55]. Identifying deficient factors and replacing them using fresh-frozen plasma, cryoprecipitate and platelets, when appropriate, is the current therapeutic approach.

Surgical treatment of oral lesion in liver transplantation pat- 
Lins et al. Transplantation Technology 2014,

ients has excellent results when multidisciplinary approach is used. Our results have shown favorable outcomes with few complications and lower mortality rate among the group of treated patients [4]. We perform oral surgical procedures in a hospital environment under antibiotic prophylaxis, with the administration of blood products when necessary, and considering the severity of liver disease. The postoperative period is accompanied by the transplant clinic hepatology team, allowing for adequate assessment of liver and kidney function, and appropriate management of any possible complications [4]. It is important to consider that elective surgery is associated with lower morbidity and mortality in cirrhotic patients [56,57]. MELD criteria to evaluate liver disease severity should be applied when planning surgical management. Literature reports low postoperative mortality when MELD score is less than 11 [57]. The MELD score for postponing an elective surgery may vary depending on many factors, such as resources and type of surgery (major or minor surgical procedures). If the MELD score is over 15, we recommend compensation of cirrhosis prior to surgery.

\section{Chronic liver disease patients in intensive care unit}

Poor oral hygiene is common in patients under intensive care and the application of chlorhexidine has been shown to decrease ventilator associated pneumonia in Intensive Care Unit (ICU) [58]. It is important to notice that no invasive procedure should be performed in cirrhotic patients admitted to ICU. Cirrhotic subjects, needing critical care support, have higher morbidity and mortality rates than other patients admitted to intensive care. Their prognosis is influenced not only by the severity of the underlying liver disease but also by the worsening of the organ extrahepatic function [56]. However, measures improving oral hygiene are required in other to reduce the possibility of respiratory infection that worsens the clinical status of cirrhotic critical care patients.

\section{Conclusions}

Liver transplant patients are at high risk of oral infection. Dental treatment in these subjects is feasible, but it should be performed by a multidisciplinary team. We describe an oral treatment protocol that has been successfully applied in liver transplantation patients in Northeast Brazil.

\section{List of abbreviations}

CLD: Chronic liver disease

DNA: Deoxyribonucleic acid

$\mathrm{PH}$ : Portal hypertension

PLA: Pyogenic liver abscess

CMV: Cytomegalovirus

EBV: Epstein-barr virus

MCU: Mucocutaneous ulcer

PTLD: Posttransplant lymphoproliferative disorder

HCV: Hepatitis C virus

ALD: Alcoholic liver disease

MELD: Model for end-stage of liver disease

DMFT index: Number of decayed/missing/filled teeth

\section{ICU: Intensive care unit}

\section{Competing interests}

The authors declare that they have no competing interests.

Authors' contributions

\begin{tabular}{|l|c|c|}
\hline Authors' contributions & LL & JB \\
\hline Research concept and design & $\checkmark$ & $\checkmark$ \\
\hline Collection and/or assembly of data & $\checkmark$ & -- \\
\hline Data analysis and interpretation & $\checkmark$ & $\checkmark$ \\
\hline Writing the article & $\checkmark$ & -- \\
\hline Critical revision of the article & $\checkmark$ & $\checkmark$ \\
\hline Final approval of article & $\checkmark$ & $\checkmark$ \\
\hline
\end{tabular}

Acknowledgement and funding

This work was supported by the Federal University of Bahia (grant 4244) and FAPESB/National Council for Scientific and Technological Development (CNPq)/the Brazilian Ministry of Health (grant EFP 00009556).

\section{Publication history}

Senior Editor: Henk Jan Schuurman, University of Minnesota, USA. EIC: Stephen C Strom, Karolinska Institute, Sweden.

Received: 29-Jul-2014 Final Revised: 07-Sep-2014

Accepted: 08-Sep-2014 Published: 20-Sep-2014

\section{References}

1. Brazil. Ministério da Saúde. Sistema de informação sobre mortalidade. 2011. | Website

2. Berzigotti A, Seijo S, Reverter E and Bosch J. Assessing portal hypertension in liver diseases. Expert Rev Gastroenterol Hepatol. 2013; 7:141-55. | Article | PubMed

3. Kim SI, Kim YJ, Choi JY, Yoon SK, Choi HJ, Na GH, You YK, Kim DG and Kang $\mathrm{MW}$. Strategies to reduce infectious complication using epidemiologic data analysis in liver transplant recipients. Transplant Proc. 2013; 45:3061-4. | Article | PubMed

4. Lins L, Bittencourt PL, Evangelista MA, Lins R, Codes L, Cavalcanti AR, Parana $R$ and Bastos J. Oral health profile of cirrhotic patients awaiting liver transplantation in the Brazilian Northeast. Transplant Proc. 2011; 43:1319-21. | Article | PubMed

5. Guggenheimer J, Mayher D and Eghtesad B. A survey of dental care protocols among US organ transplant centers. Clin Transplant. 2005; 19:15-8. | Article | PubMed

6. Li X, Kolltveit KM, Tronstad L and Olsen I. Systemic diseases caused by oral infection. Clin Microbiol Rev. 2000; 13:547-58. | Article | PubMed Abstract | PubMed Full Text

7. Seymour GJ, Ford PJ, Cullinan MP, Leishman S and Yamazaki K. Relationship between periodontal infections and systemic disease. Clin Microbiol Infect. 2007; 13 Suppl 4:3-10. | Article I PubMed

8. Yang J, Liu SY, Hossaini-Zadeh M and Pogrel MA. Brain abscess potentially secondary to odontogenic infection: case report. Oral Surg Oral Med Oral Pathol Oral Radiol. 2014; 117:e108-11. | Article | PubMed

9. Ohyama H, Nakasho K, Yamanegi K, Noiri Y, Kuhara A, Kato-Kogoe N, Yamada N, Hata M, Nishimura F, Ebisu S and Terada N. An unusual autopsy case of pyogenic liver abscess caused by periodontal bacteria. Jpn J Infect Dis. 2009; 62:381-3. | PubMed

10. Kim YH, Yoon HJ, Park CW, Kim JH, Lee MK, Kim KB, Na DJ and Kim JM. [A case of liver abscess caused by Fusobacterium nucleatum in a patient with recurrent periodontal diseases]. Korean J Gastroenterol. 2011; 57:42-6. | Article | PubMed

11. Wagner KW, Schon R, Schumacher M, Schmelzeisen R and Schulze D. Case report: brain and liver abscesses caused by oral infection with Streptococcus intermedius. Oral Surg Oral Med Oral Pathol Oral Radiol 
Lins et al. Transplantation Technology 2014,

http://www.hoajonline.com/journals/pdf/2053-6623-2-2.pdf

doi: $10.7243 / 2053-6623-2-2$

Endod. 2006; 102:e21-3. | Article | PubMed

12. Umeda M, Minamikawa T, Komatsubara $\mathrm{H}$, Shibuya $\mathrm{Y}$, Yokoo $\mathrm{S}$ and Komori $T$. Necrotizing fasciitis caused by dental infection: a retrospective analysis of 9 cases and a review of the literature. Oral Surg Oral Med Oral Pathol Oral Radiol Endod. 2003; 95:283-90. | Article I PubMed

13. Pizzo G, Guiglia R, Lo Russo L and Campisi G. Dentistry and internal medicine: from the focal infection theory to the periodontal medicine concept. Eur J Intern Med. 2010; 21:496-502. | Article | PubMed

14. Gulati M, Anand V, Jain N, Anand B, Bahuguna R, Govila V and Rastogi $P$. Essentials of periodontal medicine in preventive medicine. Int $\mathrm{J}$ Prev Med. 2013; 4:988-94. | PubMed Abstract | PubMed Full Text

15. Parahitiyawa NB, Jin LJ, Leung WK, Yam WC and Samaranayake LP. Microbiology of odontogenic bacteremia: beyond endocarditis. Clin Microbiol Rev. 2009; 22:46-64. | Article | PubMed Abstract | PubMed Full Text

16. Tomas I, Alvarez M, Limeres J, Potel C, Medina J and Diz P. Prevalence, duration and aetiology of bacteraemia following dental extractions. Oral Dis. 2007; 13:56-62. I Article I PubMed

17. Roberts GJ, Radford P and Holt R. Prophylaxis of dental bacteraemia with oral amoxycillin in children. Br Dent J. 1987; 162:179-82. | Article I PubMed

18. Roberts GJ, Simmons NB, Longhurst P and Hewitt PB. Bacteraemia following local anaesthetic injections in children. Br Dent J. 1998; 185:295-8. | Article | PubMed

19. Roberts G J, Gardner P and Simmons N A. Optimum sampling time for detection of odontogenic bacteraemia in children. Int J Cardiol 1992; 35:311-315. | Article

20. Lucas V and Roberts GJ. Odontogenic bacteremia following tooth cleaning procedures in children. Pediatr Dent. 2000; 22:96-100. PubMed

21. Debelian GJ, Olsen I and Tronstad L. Anaerobic bacteremia and fungemia in patients undergoing endodontic therapy: an overview. Ann Periodontol. 1998; 3:281-7. | Article | PubMed

22. Curtis MA, Zenobia C and Darveau RP. The relationship of the oral microbiotia to periodontal health and disease. Cell Host Microbe. 2011; 10:302-6. | Article | PubMed Abstract | PubMed Full Text

23. Souto R et al. Prevalence of "non-oral" pathogenic bacteria in subgingival biofilm of subjects with chronic periodontitis. Braz J Microbiol. 2006; 37:208-215. | Article

24. Barbero P, Garzino Demo MG, Milanesio M and Ottobrelli A. [The dental assessment of the patient waiting for a liver transplant]. Minerva Stomatol. 1996; 45:431-9. | PubMed

25. Niederhagen B, Wolff M, Appel T, von Lindern JJ and Berge S. Location and sanitation of dental foci in liver transplantation. Transpl Int. 2003; 16:173-8. | Article | PubMed

26. Guggenheimer J, Eghtesad B, Close JM, Shay C and Fung JJ. Dental health status of liver transplant candidates. Liver Transpl. 2007; 13:280-6. | Article | PubMed

27. Helenius-Hietala J, Aberg F, Meurman JH and Isoniemi H. Increased infection risk postliver transplant without pretransplant dental treatment. Oral Dis. 2013; 19:271-8. I Article I PubMed

28. Hernandez G, Arriba L, Jimenez C, Bagan JV, Rivera B, Lucas M and Moreno $E$. Rapid progression from oral leukoplakia to carcinoma in an immunosuppressed liver transplant recipient. Oral Oncol. 2003; 39:8790. | Article | PubMed

29. Haagsma EB, Hagens VE, Schaapveld M, van den Berg AP, de Vries EG, Klompmaker IJ, Slooff MJ and Jansen PL. Increased cancer risk after liver transplantation: a population-based study. J Hepatol. 2001; 34:84-91. | Article | PubMed

30. Jimenez C, Marques E, Loinaz C, Romano DR, Gomez R, Meneu JC, Hernandez-Vallejo G, Alonso O, Abradelo M, Garcia I and Moreno E. Upper aerodigestive tract and lung tumors after liver transplantation. Transplant Proc. 2003; 35:1900-1 | Article | PubMed

31. Lins Kusterer and LEF. Oral Diseases and Liver Pre and PostTransplantation Disorders. J Transplant Technol Res. 2011; S1:001. I Pdf
32. Webb BC, Thomas CJ, Willcox MD, Harty DW and Knox KW. Candidaassociated denture stomatitis. Aetiology and management: a review. Part 1. Factors influencing distribution of Candida species in the oral cavity. Aust Dent J. 1998; 43:45-50. | Article I PubMed

33. Olczak-Kowalczyk D, Pawlowska J, Garczewska B, Smirska E, Grenda R, Syczewska $\mathrm{M}$ and Kowalczyk W. Oral candidiasis in immunosuppressed children and young adults after liver or kidney transplantation. Pediatr Dent. 2010; 32:189-94. | Article | PubMed

34. Rabkin JM, Oroloff SL, Corless CL, Benner KG, Flora KD, Rosen HR and Olyaei AJ. Association of fungal infection and increased mortality in liver transplant recipients. Am J Surg. 2000; 179:426-30. | Article I PubMed

35. Morard I, Dumortier J, Spahr L, Hadengue A, Majno P, Morel P, Mentha $\mathrm{G}$ and Giostra E. Conversion to sirolimus-based immunosuppression in maintenance liver transplantation patients. Liver Transpl. 2007; 13:65864. | Article | PubMed

36. Ram R, Swarnalatha G, Neela P and Dakshinamurty KV. Sirolimus-induced aphthous ulcers which disappeared with conversion to everolimus. Saudi J Kidney Dis Transpl. 2008; 19:819-20. | Article | PubMed

37. Macario-Barrel A, Tanasescu S, Courville P, Redonnet M, Cordel N, Lauret $\mathrm{P}$ and Joly $\mathrm{P}$. [Mouth ulcers in patients receiving tacrolimus]. Ann Dermatol Venereol. 2001; 128:1327-9. | PubMed

38. Vermeulen T, Rodrigus IE, Vrints CJ and Conraads V. Severe stomatitis complicating immune-suppressive switch after cardiac transplantation. Acta Chir Belg. 2010; 110:339-41. I PubMed

39. Weng RR, Foster CE, 3rd, Hsieh LL and Patel PR. Oral ulcers associated with mycophenolate mofetil use in a renal transplant recipient. Am J Health Syst Pharm. 2011; 68:585-8. | Article I PubMed

40. Olczak-Kowalczyk D, Pawlowska J, Cukrowska B, Kluge P, Witkowska-Vogtt E, Dzierzanowska-Fangrat K, Wrzesniewska D, Smirska E and Grenda R. Local presence of cytomegalovirus and Candida species vs oral lesions in liver and kidney transplant recipients. Ann Transplant. 2008; 13:2833. | PubMed

41. Burke EM, Karp DL, Wu TC and Corio RL. Atypical oral presentation of herpes simplex virus infection in a patient after orthotopic liver transplantation. Eur Arch Otorhinolaryngol. 1994; 251:301-3. | Article | PubMed

42. Hernandez G, Jimenez C, Arriba L, Moreno E and Lucas M. Resolution of oral ulcerations after decreasing the dosage of tacrolimus in a liver transplantation recipient. Oral Surg Oral Med Oral Pathol Oral Radiol Endod. 2001; 92:526-31. | Article | PubMed

43. Hernadi K, Szalmas A, Mogyorosi R, Czompa L, Veress G, Csoma E, Marton I and Konya J. Prevalence and activity of Epstein-Barr virus and human cytomegalovirus in symptomatic and asymptomatic apical periodontitis lesions. J Endod. 2010; 36:1485-9. | Article I PubMed

44. Herrmann K, Frangou P, Middeldorp J and Niedobitek G. Epstein-Barr virus replication in tongue epithelial cells. J Gen Virol. 2002; 83:2995-8. | Article | PubMed

45. Hart M, Thakral B, Yohe S, Balfour HH, Jr., Singh C, Spears M and McKenna RW. EBV-positive Mucocutaneous Ulcer in Organ Transplant Recipients: A Localized Indolent Posttransplant Lymphoproliferative Disorder. Am J Surg Pathol. 2014. | Article | PubMed

46. Oettinger-Barak O, Machtei EE, Barak S, Baruch Y, Ardekian L and Peled $M$. Periodontal changes in liver cirrhosis and post-transplantation patients. II: radiographic findings. J Periodontol. 2002; 73:313-6. | Article I PubMed

47. Neff GW, Kemmer N, Duncan C and Alsina A. Update on the management of cirrhosis - focus on cost-effective preventative strategies. Clinicoecon Outcomes Res. 2013; 5:143-52. | Article | PubMed Abstract | PubMed Full Text

48. Guggenheimer J and Moore PA. Xerostomia: etiology, recognition and treatment. J Am Dent Assoc. 2003; 134:61-9. | Article | PubMed

49. Lins L and Pereira Falcão A F. Oral Health Status of Cirrhotic Patients in List of Liver Transplantation and of Viral Hepatitis Carriers. J Transplant Technol Res. 2012; 2:3. I Pdf

50. World Health Organization. Oral health surveys: Basic methods. $4^{\text {th }}$ edition. Geneva, 1997. I Pdf 
Lins et al. Transplantation Technology 2014,

http://www.hoajonline.com/journals/pdf/2053-6623-2-2.pdf

51. Page RC and Eke PI. Case definitions for use in population-based surveillance of periodontitis. J Periodontol. 2007; 78:1387-99. | Article I PubMed

52. Leroy R, Eaton KA and Savage A. Methodological issues in epidemiological studies of periodontitis--how can it be improved? BMC Oral Health. 2010; 10:8. | Article | PubMed Abstract | PubMed Full Text

53. Krasse B. Risk of caries: a practical guide to assessment and controle. Quintessence: São Paulo, 1988.

54. Lins L, Paraná R, Reis, SRA and Falcão AFP. Primary biliary cirrhosis and Sjögren's syndrome: insights for the stomatologist. Case Rep Gastroenterol. 2014; 8:251-6. | Article

55. Afdhal N, McHutchison J, Brown R, Jacobson I, Manns M, Poordad F Weksler B and Esteban R. Thrombocytopenia associated with chronic liver disease. J Hepatol. 2008; 48:1000-7. | Article | PubMed

56. Rocco JR and Soares M. Prognóstico do paciente cirrótico admitido na terapia intensiva. Rev Bras Ter Intensiva. 2010; 22:11-18. | Article

57. Teh SH, Nagorney DM, Stevens SR, Offord KP, Therneau TM, Plevak DJ, Talwalkar JA, Kim WR and Kamath PS. Risk factors for mortality after surgery in patients with cirrhosis. Gastroenterology. 2007; 132:1261-9. Article | PubMed

58. Wiener-Kronish JP and Dorr HI. Ventilator-associated pneumonia: problems with diagnosis and therapy. Best Pract Res Clin Anaesthesiol. 2008; 22:437-49. | Article | PubMed Abstract | PubMed Full Text

\section{Citation:}

Lins L and Bastos J. Oral health protocol for liver transplant patients. Transplant Technol. 2014; 2:2.

http://dx.doi.org/10.7243/2053-6623-2-2 